\title{
Consumers' Knowledge Discrepancy and Confusion in Intent to Purchase Farmed Fish
}

\author{
Mohammed Ziaul Hoque, , Md. Nurul Alam ${ }^{2, *}$ \\ ${ }^{1}$ School of Business and Economics, UiT The Arctic University of Norway, Breivangviegn 23, 9010 \\ Troms $\varnothing$, Norway; and Finance, University of Chittagong, Bangladesh; \\ ${ }^{2}$ Coats Bangladesh Limited, Sagorika Road, Chittagong 4219, Bangladesh; mnaraju@ rocketmail.com \\ *Correspondence: mohammed.z.hoque@uit.no
}

\begin{abstract}
Purpose-The purpose of the paper is to examine the influence of consumers' perceived knowledge, knowledge discrepancy, and confusion on the intention to purchase farmed fish (FF) via a survey design regarding perceptions, buying and consumption practices of urban households in Chittagong, Bangladesh.

Design/methodology/approach-The samples of 498 households were selected from a stratified cluster from the Chittagong city and interviewed using a structured questionnaire. The data have been analysed using, Confirmatory Factor Analysis, and Structural Equation Modelling.

Findings-The results show that consumers' subjective knowledge (SK) is significant for purchase intention whereas objective knowledge (OK) is not. Again, the SK, OK, knowledge discrepancy, and confusion have no influences in forming consumers' attitude towards FF. However, consumers who overestimate their actual level of knowledge hold negative attitude toward FF and vice versa. Further, consumers' OK affects their confusion adversely although it does not influence the purchase intention significantly.

Practical implications-If the marketers can frame a more engaging means of communication and knowledge enhancement plan, consumers' attitude and purchase intention regarding FF will be signified.

Originality/value-This is the first study that fundamentally contributes to the scientific research in that it measures the knowledge discrepancy of consumers regarding FF. In addition, this study substantiates that low objective knowledge leads to confuse consumers at the time of purchasing. The effect of overestimating the level of knowledge as well as underestimating the level of knowledge in explaining purchase intention of FF would be a supplementary addition.
\end{abstract}

Keywords Farmed Fish, Knowledge, Confusion, Purchase Intention, Emerging Market, Bangladesh.

\subsection{Introduction}

Past couple of decades are marked by an upward trend in the consumption of fishes because of their nutritional value and dietary features. Keeping pace with this trend, an alternative fish farming method other than wild caught has been becoming a good substitute to meet the excessive demand for fish. Given its health value, farmed fishes (FF) also contain less contamination such as mercury, levels of cobalt, copper, and cadmium than do contain those of wild (Claret et al., 2014). Hence, the immense need for aquaculture to meet the demand for fish supply is urged from different actors of the community. However, currently, an increase in socio-environmental conflicts in relation to finfish aquaculture is reported (Ertör and Ortega-cerdà, 2015). Thus, consumers are worried about the environmental justice, a claim which can be justified by the use of best available techniques and practices including usage of closed containers instead of open cages, sustainable sourcing of feed, labeling and monitoring systems, and an even, transparent and participatory governance (Liu, Olaussen and Skonhoft, 2011). Additionally, literature recommends that consumers do not hold a conservative attitude to aquaculture, rather they do acknowledge the significance of aquaculture in alleviating the recent stagnation of fish supply (Ertör and Ortega-cerdà, 2015). 
Consumers of FF have a positive attitude toward general aquaculture, but their attitude get negatively influenced when the issues of environment appears (Froehlich et al., 2017). Different reasons were found behind these mixed and inverse impressions of consumers of FF including negative media report, lack of knowledge, ambiguous production process and consumption pattern etc (Verbeke et al., 2007). This ambiguity leads to confuse the consumers while the awareness and knowledge of consumer confusion are relevant to successful marketing because confused consumers are less likely to make rational buying decisions and to choose products offering the best value for money (Huffman, Cynthia and Kahn, 1998).

In Asia and the Pacific region, aquaculture in terms of production has continued to grow at a rapid rate since 2005. Current trends show that FF species will play a major role in determining whether Asian aquaculture will be successful in achieving its growth potential. In South-Asia, Bangladesh is one of the world's leading fish producing countries with a total production of 41.34 lakh MT in 2016-17 (DoF, 2017), ranking third in the world in terms of inland fish production. Moreover, in Bangladesh, aquaculture is set to grow further, and it now provides around half the total market supply of fish for direct human consumption where capture fisheries are still the main source of fish in the diet (Shamsuzzaman et al., 2017). However, as an industry, aquaculture is still in its relative infancy, thus knowledge of the nutritional requirements of most fish species is rather limited compared to poultry and other livestock. Moreover, almost all-existing literature about aquaculture in Bangladesh belong to addressing the supply chains. Therefore, the demand side, for example, consumers' perceptions of and knowledge regarding FF, has been studied little although the need for gaining insight from the consumers' perception perspective regarding farmed fish has been identified as a particularly key factor. Thus, this study aims to fill in this knowledge gap.

In order to gauge consumers' knowledge towards a particular product, subjective evaluation is a popular technique (Selnes and Gronhaug, 1986). Many researchers have applied this method to estimate the consumers' perception (CP) of farmed fish (FF) focusing consumers' buying and consumption patterns (Claret et al., 2014), Furthermore, Fernández-Polanco and Luna (2010) in their research have investigated the effects of knowledge on consumers' perceptions and consumption of FF. However, they constructed the scale of knowledge with open-ended questions considering demographic factors and consumption habits only, which is not complete. Additionally, the literature lacks showing the consumers' knowledge discrepancy and confusion and its effects on their attitude, and willingness to purchase of FF. Thus, the study aims to support efforts to estimate consumer intention to buy FF by exploring consumers' knowledge, knowledge discrepancies, confusion and attitude towards aquaculture in general and towards farmed fish in particular. To achieve the objective, the study has assessed the relationship between subjective and objective knowledge, measured their differences (knowledge-discrepancy), and examined the effect of knowledge, knowledge-discrepancy, and consumers' confusion on consumers' attitude, and on the purchase intention based on the conceptual model using a questionnaire survey. Exploratory Factor analysis, Confirmatory Factor Analysis and Structural Equation Modelling were the main research methods employed. The study also examined the validity of the relationships between consumers' knowledge, knowledge discrepancy, confusion, and the evaluations of FF.

The structure of the study is as follows. The review of literature along with the development of hypotheses, and a conceptual model were first demonstrated, followed by a discussion of data and empirical model. Then the research results were discussed, managerial and policy implications, 
and concluding remarks were given and the paper ends up with limitation and direction for future research.

\subsection{Theory and Hypotheses Development}

Consumers decision-making process in buying a healthy, nutritious and sustainable product is not simple rather complex. Not all consumers' behavioural patterns are univocally consistent with their interests, preferences, or attitudes. However, Knowledge is a major catalyst in this regard and it may influence to reshape consumers' attitude and, in turn, to minimize the attitude-behaviour gap (Takahashi, 1999).

Accordingly, Research corroborates that consumers' perceived knowledge regarding a particular product or, choice plays a crucial role in determining consumers' decision-making process (Hoque, Alam and Nahid, 2018). Interestingly, despite having low knowledge, consumer holds a quite specific opinion about aquaculture (Verbeke and Bruns $\varnothing$, 2005). To explain this behaviour, research suggests that consumers' perception, in general, regarding farmed fish species may be based on emotion and preconceived belief rather than on objective knowledge (Schlag and Ystgaard, 2013). Since new information can sway the perceptions of the low knowledgeable people (Aertsens et al., 2011) consumers' perception regarding aquaculture can be easily shaped through manipulative data. Hence, we forwarded a model (Figure 1) that incorporates knowledge (both subjective and objective), knowledge discrepancy and confusion with attitudes towards the purchase intention of FF.

This paper's conceptual model, including hypotheses, is presented in Figure 1.



Figure 1: Conceptual Model: demonstrates the hypotheses drawn in support of the literature with using structural equation model.

\subsection{Subjective Knowledge (SK) and Objective Knowledge (OK)}

Subjective knowledge is the individual's perception of how much s/he knows (Brucks, 1985). In other words, it refers to people's subjective perceptions of what or how much they know or, they are familiar with a product or choice (Park et al., 1994). On the other hand, Objective 
knowledge is what a consumer actually knows (Brucks, 1985). Objective knowledge helps in enriching the acquired information and thus in improving confidence (Selnes and Gronhaug, 1986). Both subjective and objective knowledge positively influence consumers' preference for choice attributes that a consumer search for while making a purchasing decision (Brucks, 1985). Therefore, based on the discussion above, the following hypotheses are formulated:

Hypothesis 1a (H1a): Subjective knowledge positively influences the attitude towards farmed fish.

Hypothesis 2a (H2a): Objective knowledge positively influences the attitude towards farmed fish.

Research suggests that in order to have a favourable repercussion in making a food choice, consumers must have a sufficient level of knowledge or, familiarity regarding the attributes of that particular product (Verbeke, 2008). In line with this, therefore, it is expected that both subjective and objective knowledge regarding farmed fish will have a positive relationship with farmed fish purchase intention and consumption.

In order to investigate if this is the case, the following hypotheses are formulated:

Hypothesis 1b (H1b): Subjective knowledge positively influences the purchase intention of FF. Hypothesis $2 \mathbf{b}(\mathrm{H} 2 \mathrm{~b})$ : Objective knowledge positively influences the purchase intention of FF.

\subsection{Consumers' Knowledge Discrepancy}

People do not always accurately perceive how much or how little they know (House et al., 2004). People, in general, are supposed to consider themselves to be more knowledgeable than they actually are and vice versa (Taylor and Brown, 1988). Regarding FF, this implies that consumers often think they know what a particular FF species stands for whereas in reality their knowledge is merely constructed. Taylor and Brown (1988) also reported that those who tend to believe themselves more knowledgeable are less likely to acquire correct information, ending up with retaining the incorrect information they knew formerly. When it comes to acquiring correct information regarding FF, they may be retained with the incorrect knowledge, and thereby there may arise a discrepancy between subjective knowledge and objective knowledge. In light of this discussion, the following hypotheses are forwarded:

Hypothesis 3 (H3): Consumers have a discrepancy between their subjective and objective knowledge regarding FF.

Hypothesis 3a (H3a): Consumers' knowledge discrepancy has a negative influence on attitude towards FF.

Hypothesis 3b (H3b): Consumers' knowledge discrepancy has a negative influence on purchase intention of FF.

Whether consumers who overestimate their level of knowledge buy more than who underestimate their knowledge level is unknown, till to date, in the area of FF consumption. Additionally, studying this relationship seemed like a natural course of action. Recently, Gunne and Matto (2017) uses consumers' discrepancy to investigate the influence of knowledge on consumers' green purchase. As asymmetric information are lacked regarding FF, we believe that knowledge are required to understand the fundamentals of aquaculture. Based on the aforesaid discussion, the following hypotheses are posited:

Hypothesis 3c (H3c): Consumers' discrepancy with overestimate is negatively associated with the attitude towards FF. 
Hypothesis 3d (H3d): Consumers' discrepancy with underestimate is positively associated with the attitude towards FF.

\subsection{Consumers' Confusion Regarding FF}

Knowledge, a compound esoteric concept embedded in particular social construct, is shaped by various surrounding context (Fernie et al., 2003). A concrete knowledge about any particular product decreases the confusion which, in turn, is negatively associated with satisfaction (Matzler, Stieger and Füller, 2011). Hence, we formulated the following hypothesis.

Hypothesis 4 (H4): Consumers with low level of objective knowledge regarding FF are more confused than consumers with a high level of objective knowledge.

In particular, lack of knowledge and confusion about farmed fish appear to be the leading barrier to the expansion of the farmed fish market (Verbeke et al., 2007). Thereby, it can be assumed that the lack of distinguishability i.e., confusion leads to affect the attitude and purchase intention of FF. In the light of this discussion the following hypotheses are forwarded:

Hypothesis 5a (H5a): Confusion regarding FF negatively influences the attitude.

Hypothesis 5b (H5b): Confusion regarding FF negatively influences the purchase intention of FF.

\subsection{Attitude and Purchase Intention}

Attitude can be defined as an individual's reaction towards a particular choice or, attributes (Rokeach Milton, 1970). Furthermore, attitude is a psychological construct important to drive the choice decision (Lessig and Copley, 1974). Moreover, consumers' likelihood of purchasing a product or services is largely defined by the attitude they posse. For instance, a study by Hoque et al., (2018) reports that consumers of Liquid milk find the health consciousness, belief as great motivator and these variables along with several other factors largely comprehended their attitude which ultimately drove their purchase intention significantly. Considering above discussion, we hypothesize the following relationship:

Hypothesis 6 (H6): Attitude positively influences the Purchase Intention of FF.

\subsection{Materials and Methods}

This study was based on the urban area of Chittagong, which is the business hub (chief port) and the commercial centre of Bangladesh. Primary data were collected from the study area presenting a structured questionnaire administered by enumerators. To collect the representative sample, stratified and clustered random sampling procedures were employed. There are 12 administrative areas (Police Station (PS)) in Chittagong City Corporation. Each PS includes three or four small administrative areas, called ward, resulting in 41 areas in total. To ask the subjects, 10 Police Station (Bakoliya, Bayazid, Chandgaon, Hathazari, Khulshi, Patenga, Panchlaish, Double Mooring, Halishahar) of the city were randomly selected. Then, one ward from each PS has been considered randomly to recruit 50 respondents form each PS by employing convenient method. Thereby, a total of 500 (50 person* 10 PS) households who prefer and consume fish were selected randomly and two samples were finally excluded due to uselessness. The questionnaire was submitted to the consumers and they were asked to fill it in along with a face to face interview.

The fieldwork was carried out from 01 March, 2018 to 30 April, 2018. Before the final version of the survey, a pre-test survey on 15 subjects was conducted from two PS (Kotwali and Chandgaon) in the same city in order to ensure that respondent understood the questions and no 
semantic and measurement problems exist. As we did not find any major obstacles, we decided to keep the same settings for the final asking. Respondents older than the age of 20 and who are the buyer of fish was chosen for the interview. The interview on an average took 20 minutes per interviewee. The purpose of the study was stated in a cover letter and respondents were asked to answer a set of questions and statements designed to answer the questions. Descriptive analysis, EFA, CFA and SEM were the major statistical tools used in the study.

\subsection{Questionnaire and Measures}

The items for questions included in the questionnaire were developed basing on the literature review. The questionnaire was devised into three sections, wherein the first section consisted of questions regarding the measurement of SK, OK, and Confusion. The second section includes two parts: Attitude, and Purchase intention. The questionnaire concluded with the third section, wherein the respondent's demographic information was asked.

The SK of FF has been measured in the seven-point Likert scale from 'strongly disagree' (1) to 'strongly agree' (7) with the statement such as "I have in-depth knowledge to evaluate the quality of farmed fish/ have more knowledge in comparison to others/ am expert/ heard the name of production method/ know the production process etc". All of the questions were adapted from previous literatures.

Five questions have been considered to construct the OK scale. Among the five, one questions with false and the rest of them are framed with the true statement. The construct of OK covered consumers' understandings about the price, sources of omega-3, dietary fibre, fat, and the availability of farmed fish species.

A new variable named 'discrepancy' is constructed to demonstrate the difference between subjective and objective knowledge: a positive discrepancy refers that respondents have higher SK than OK. On the other hand, negative discrepancy signifies their undervaluation of objective (actual) knowledge and their perception as less knowledgeable than they actually are. The discrepancy has been measured with the difference between the $\mathrm{Z}$ score of objective and subjective knowledge of each, in which $\mathrm{Z}$ score is calculated using the formula, $\mathrm{Z}=(\mathrm{x}$ - mean)/standard deviation, where $x$ represents the observed value (Burns and Burns, 2008). The rationale behind the application of $\mathrm{Z}$ score, in this context, is that it relabels each score in terms of its deviation.

The Confusion scale is divided into two categories such as general confusion and specific confusion. The variable of general confusion has been adapted from the study of Gunne and Matto (2017) and the variables of specific confusions are compiled by other studies basing on the existing literature (Ermeç Sertoğlu and Kavak, 2017). The general confusion of FF has been measured in the seven-point Likert scale from 'strongly disagree' (1) to 'strongly agree' (7) with the statement "I feel confused regarding the meaning of Aquaculture/farmed fish". The construct of specific confusion included perceived level of confusion on the risk level, benefit, awareness, and lacks information regarding FF.

The scale of general attitude has been constructed with the six seven-point bi-polar scale such as bad to good, negative to positive, unfavourable to favourable, dull to exciting, terrible to great and unsatisfied to satisfied (Lord, 1994). Finally, the purchase intention incorporated consumers' intent to purchase, intent to pay price, advertisement impact, and recommend to others to purchase. The scale for purchase intention has been constructed based on the four seven-point Likert scale. 
Each scale has been adapted from the previous studies (Barber et al., 2009; J. et al., 2016; Prebensen and Xie, 2017)

The EFA has considered four questions in the construct of attitude, three questions in subjective knowledge, three questions in confusion, and three questions in purchase intention and each of the constructs has eigenvalues greater than 1 (see the Table 2) explaining $66.63 \%$ of total variance.

\subsection{Results and discussion}

\subsection{Demographic profile of the respondents}

The survey is conducted among the subjects who shop at least food for family frequently, of the participants. The majority $(82.1 \%)$ of the respondents was male (Table 2$)$, the rest $17.9 \%(89$ participants) was $40-50$ age group cluster that accounted for 151 members $(30.3 \%)$. And the rest $17.5 \%, 10.0 \%, 3.2$ female. The largest age group belonged to the 20-30 strata, with 191 members (38.4\%), followed by the $\%, 0.6 \%$ pertained to the $50-60,30-40,60-70$, and above 70 age-group respectively.

\subsection{Measurement model.}

Kaiser-Meyer-Olkin (KMO) and Bartlett's Test of Sphericity, as suggested by Pallant, 2007, have been conducted prior to factor analysis. The KMO test achieved 0.723 (Table 1) and a significant $p$ value is attained $(<0.01)$ in the Bartlett's Test of Sphericity. The measurement model demonstrated an excellent model appropriateness with the data having Chi square $\left(\chi^{2}\right)=166.124$, Degree of Freedom $(\mathrm{df})=106, \mathrm{p}$ value $=0.00$, Root mean square error approximation (RMSEA) $=0.046$, Incremental fit index $(\mathrm{IFI})=0.962$, Tucker-Lewis index $(\mathrm{TLI})=0.943$, Comparative fit index $(\mathrm{CFI})=0.960$, Goodness-of-fit index $(\mathrm{GFI})=0.937$, and $\chi^{2} / \mathrm{df}=1.567$.

Table-1: Kaiser-Meyer-Olkin (KMO) and Bartlett's Test of Sphericity.

KMO and Bartlett's Test

\begin{tabular}{cll}
\hline Kaiser-Meyer-Olkin Measure of Sampling Adequacy. & 0.723 \\
\hline \multirow{3}{*}{ Bartlett's Test of Sphericity } & Approx. Chi-Square & 2107.474 \\
\cline { 2 - 3 } & Df & 78 \\
\cline { 2 - 3 } & Sig. & 0.000 \\
\hline & Note: df= Degree of Freedom; Sig. Significance
\end{tabular}

Afterwards, EFA was run (Table 2) to test the convergent validity of the proposed constructs and to validate the factor loadings (Hair et al., 1998). Furthermore, Cronbach's alpha, which is considered to test the internal consistency, is calculated. For each of the four components, the minimum cut off value, as suggested by Hair et al., (2010) greater than 0.6 was achieved. However, it is well recommended that Cronbach's alpha be greater than 0.70 . On the other side, composite reliability $(\rho)$ is well above the recommended threshold level of 0.70 (Hair et al., 2006). Further, each construct obtained the Average Variance Extracted (AVE) value of above 0.50, indicating the convergent validity for each construct (Hair et al., 2006). 
Table 2: Measurement Model.

\begin{tabular}{|c|c|c|c|c|c|}
\hline Constructs and Items & $\lambda$ & $\alpha$ & $\rho$ & Eigenvalues & AVE \\
\hline Attitude & & 0.83 & 0.91 & 3.084 & 0.72 \\
\hline Terrible to Great & 0.873 & & & & 0.78 \\
\hline Unsatisfied to Satisfied & 0.866 & & & & 0.76 \\
\hline Dull to Exciting & 0.865 & & & & 0.76 \\
\hline Bad to Good & 0.779 & & & & 0.66 \\
\hline Subjective Knowledge & & 0.79 & 0.87 & 2.421 & 0.69 \\
\hline Knows a lot than average person & 0.848 & & & & 0.73 \\
\hline Friends consider as an expert in the domain of FF & 0.828 & & & & 0.69 \\
\hline Have depth knowledge to evaluate the quality of FF & 0.818 & & & & 0.67 \\
\hline Confusion & & 0.68 & 0.82 & 1.698 & 0.60 \\
\hline Lack of information makes confused about FF & 0.829 & & & & 0.69 \\
\hline Little awareness may be caused to be confused about FF & 0.764 & & & & 0.63 \\
\hline Confused about the risk level of FF & 0.729 & & & & 0.52 \\
\hline Purchase Intention & & 0.60 & 0.79 & 1.146 & 0.56 \\
\hline Intend to purchase when next time buy Fish & 0.795 & & & & 0.67 \\
\hline Advertisements impact purchase decision & 0.756 & & & & 0.58 \\
\hline Would pay any price & 0.684 & & & & 0.52 \\
\hline
\end{tabular}

Again, to test the discriminant validity, the AVE of each construct is compared with the respective correlations between the respective constructs (Table 3) and estimates for all variance extracted were greater than their respective squared correlation, suggesting that each construct has its uniqueness and that no multicolinearity problem exists in our data set. Furthermore, a value higher than 0.001 for the determinant of the correlation matrix of 0.001 in the model was found (determinant=0.014), also showing no multicollinearity problems (Field, 1999).

Table 3: Descriptive Statistics and Correlations among latent Constructs.

\begin{tabular}{lcccccc}
\hline Items & Mean & S.D & ATT & SK & CON & PI \\
\hline${\text { Attitude }(\mathrm{ATT})^{\dagger}}^{\dagger}$ & 4.95 & 1.24 & $(0.72)$ & 0.004 & 0.002 & 0.029 \\
\hline Subjective Knowledge (SK) $^{\dagger}$ & 4.23 & 1.38 & .060 & $(0.69)$ & 0.025 & 0.009 \\
\hline${\text { Confusion }(\mathrm{CON})^{\dagger}}^{\dagger}$ & 4.57 & 1.25 & .048 & -.157 & $(0.60)$ & 0.001 \\
\hline Purchase Intention $(\mathrm{PI})^{\dagger}$ & 3.34 & 1.07 & -.171 & -.093 & -.027 & $(0.56)$ \\
\hline
\end{tabular}

${ }^{\dagger}$ measured in Likert 7-point scale;

Note: The diagonal values represents AVE. The lower diagonal value represent correlation between the constructs whereas the upper diagonal values represent squared correlation between the constructs; S.D= Standard Deviation.

\subsection{Structural Model}

\subsubsection{Assessment of Fitness for Structural Model}

The study develops a Structural Equation Model (SEM). The SPSS and AMOS Graphics, 24.00 version were used for factor analysis and the path model analysis. To gauge the fitness of the model, several goodness-of-fit test statistics were deployed (Brown, 2006). The results of all indices from each category (Absolute Fit Measure, Incremental Fit Measure, and Parsimonious Fit Measure) meet the requirements provided for an adequate evidence of model fit (Table 4), indicating construct validity (Haque et al., 2015). 
Table 4: Goodness of fit Indices.

\begin{tabular}{cccc}
\hline Category & Indices & Recommended least value & Attained value \\
\hline Absolute Fit & $\chi^{2}$ & $\mathrm{p}>0.05$ & Significant at $<0.01$ \\
\cline { 2 - 4 } & RMSEA & $<0.08^{\mathrm{a}, \mathrm{d}}$ & 0.043 \\
\cline { 2 - 4 } & GFI & $>0.90^{\mathrm{b}, \mathrm{c}}$ & 0.964 \\
\hline Incremental Fit & AGFI & $>0.90^{\mathrm{e}}$ & 0.933 \\
\hline Parsimonious Fit & CFI & $>0.90^{\mathrm{a}}$ & 0.921 \\
\hline Noted $\left.\chi^{2}\right)$ & $<3-5^{\mathrm{e}}$ & 1.923 \\
\hline
\end{tabular}

Note: RMSEA = root mean square error approximation; GFI = goodness-of-fit index; AGFI = adjusted goodness-of-fit index; CFI $=$ comparative fit index; ${ }^{\mathrm{a}}\left(\right.$ Hair, Black, WC, Babin and Anderson, 2010); ${ }^{\mathrm{b}}$ (Forza and Filippini, 1998); ${ }^{\mathrm{c}}($ Greenspoon and Saklofske, 1998), ${ }^{\mathrm{d}}$ (Awang, 2012) ${ }^{\mathrm{e}}$ (Haque et al., 2015)

As assessment of structural model revealed that, the data fit well with the proposed constructs. The $\chi^{2}$, RMSEA, GFI, values are well above the recommended level, suggesting a good absolute fit index. The values for AGFI, CFI and Normed $\chi^{2}$ also satisfy the recommended level, ensuring both incremental and parsimonious fit respectively.

\subsubsection{Result of Hypotheses Test and Discussion.}

To test the hypothesized relationship, several hypotheses were developed and tested in the light of previous research. The Table 5 below shows the results to provide support for the acceptance and rejection of the hypotheses.

Table 5: Results of Structural Equation Modeling: Standardized Path Estimates. Structural Path $\begin{array}{llll}\text { Standardized path } & \text { S.E } & \text { C.R } & \text { P-Value }\end{array}$ co-efficient ( $\beta$ )

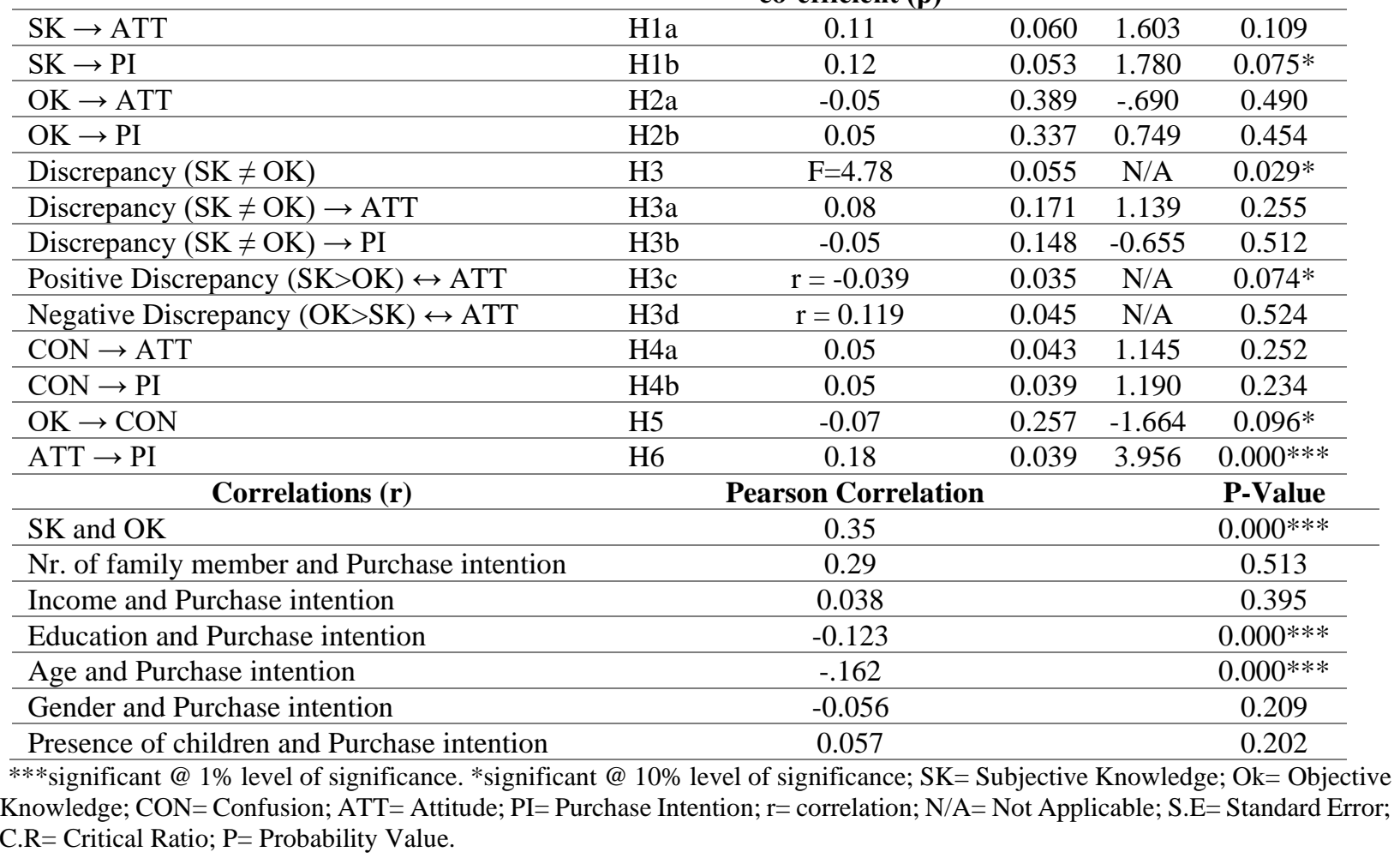

As seen from the table 5 and figure 2, of the total 13 hypotheses are tested, wherein five hypotheses are found to be statistically significant. In $\mathrm{H} 1 \mathrm{~b}$, SK is found to be significantly and positively influencing the purchase intention $(\beta=0.12, \mathrm{~S} . \mathrm{E}=0.053, \mathrm{C} . \mathrm{R}=1.780$ and $\mathrm{P}<0.10)$ while 
in hypothesis $\mathrm{H} 2 \mathrm{~b}, \mathrm{OK}$ has a positive impact on the purchase intention (PI) but the influence is not statistically significant, hence the hypothesis is not accepted. Hypotheses H1a $(\beta=0.11 ; \mathrm{S} . \mathrm{E}=$ 0.060; C.R=1.603; P>.109) and H2a $(\beta=-0.05 ; \mathrm{S} . \mathrm{E}=0.389 ; \mathrm{C} . \mathrm{R}=-.690 ; \mathrm{P}>.10)$ are not accepted, implying both $\mathrm{SK}$ and $\mathrm{OK}$ do not significantly influence the attitude toward FF consumption.

Table 6: Levene's Test for Equality of Variances

\begin{tabular}{|c|c|c|c|c|c|c|c|c|c|}
\hline & \multirow[b]{2}{*}{$\mathbf{N}$} & \multirow[b]{2}{*}{ Mean } & \multirow[b]{2}{*}{ SD } & \multirow[b]{2}{*}{ S.E } & \multicolumn{2}{|c|}{$\begin{array}{c}\text { Levene's Test for Equality } \\
\text { of Variances }\end{array}$} & \multirow[b]{2}{*}{ t-value } & \multirow[b]{2}{*}{ Sig. (2-tailed) } \\
\hline & & & & & & $\mathbf{F}$ & Sig. & & \\
\hline \multirow[t]{2}{*}{ Discrepancy } & $\mathrm{SK}<\mathrm{OK}$ & 227 & -.855 & .676 & .045 & 4.78 & 0.029 & -28.07 & 0.000 \\
\hline & $\mathrm{SK}>\mathrm{OK}$ & 271 & .716 & .573 & 035 & & & & \\
\hline
\end{tabular}

$\mathrm{SK}=$ Subjective Knowledge; OK= Objective Knowledge; N= Number of Population; $\mathrm{SD}=\mathrm{Standard}$ Deviation; F=F value; Sig.= Significance level.

The study also hypothesizes that consumers have a discrepancy between their SK and OK (H3) and the results reveal that the level of subjective knowledge and objective knowledge differs significantly in a given respondent. To test the hypothesis Levene's Test for Equality of Variances (Table 6) was applied wherein $\mathrm{F}=4.78 ; \mathrm{t}=-28.068 ; \mathrm{df}=496 ; \mathrm{S} . \mathrm{E}=0.056 ; \mathrm{P}<0.05$. Regarding $\mathrm{FF}$, this implies that consumers often think they know what a particular FF species stands for, while, in reality, their knowledge is merely constructed and vice versa.

The test result does not accept hypothesis $\mathrm{H} 3 \mathrm{a}$ and, hence, is rejected $(\beta=0.08 ; \mathrm{S} . \mathrm{E}=0.171$; $\mathrm{C} . \mathrm{R}=1.139 ; \mathrm{P}>0.10)$, indicating knowledge discrepancy has no influence in forming attitude towards the purchase intention. Again, in hypothesis $\mathrm{H} 3 \mathrm{~b}$, the result shows that knowledge discrepancy influences purchase intention negatively but the influence is not statistically significant $(\beta=-0.05 ; \mathrm{S} . \mathrm{E}=0.148 ; \mathrm{C} . \mathrm{R}=-0.655 ; \mathrm{P}>.10)$. Thereby, knowledge discrepancy does not influence consumers' attitude and purchase intention of FF. To test the hypothesis H3c, Pearson correlation test has been conducted to test the correlation between positive discrepancy and attitude. The result provides a negative relationship $(r=-0.039, \mathrm{~S} . \mathrm{E}=0.035 ; \mathrm{P}<0.10)$ between them. Hypothesis $\mathrm{H} 3 \mathrm{~d}$ revealed a positive association between negative discrepancy and attitude but the result is not statistically significant $(\mathrm{r}=0.119, \mathrm{~S} . \mathrm{E}=0.045 ; \mathrm{P}>0.10)$.

However, as observed from hypotheses $\mathrm{H} 4 \mathrm{a}(\beta=0.05 ; \mathrm{S} . \mathrm{E}=0.043 ; \mathrm{C} . \mathrm{R}=1.145 ; \mathrm{P}>.10)$ and $\mathrm{H} 4 \mathrm{~b}$ $(\beta=0.05 ; \mathrm{S} . \mathrm{E}=0.039 ; \mathrm{C} . \mathrm{R}=1.190 ; \mathrm{P}>.10)$, confusion $(\mathrm{CON})$ merely affects the attitude and purchase intention of FF. Therefore, the study rejects these hypotheses. The study also reports a significant and positive association, by accepting hypothesis $\mathrm{H} 5(\beta=0.18 ; \mathrm{S} . \mathrm{E}=0.039 ; \mathrm{C} . \mathrm{R}=3.956$; $\mathrm{P}<.01)$, between attitude and purchase intention Finally, $\mathrm{H} 6(\beta=-0.07 ; \mathrm{S} . \mathrm{E}=0.257 ; \mathrm{C} . \mathrm{R}=-1.664$; $\mathrm{P}<$.10) reveals that people who possessed lower objective knowledge about FF are more confused while buying FF than people who held higher objective knowledge.

This study attempts to explore the impact of controlling variables such as demographic factors on purchase intention. The results report that education and the age of households have a negative, significant influence on the intent to purchase of FF. The obtained results indicate that consumers who buy fish from the wet market have more intention to purchase FF than who buy fish from the super market or both. Literatures also report that age, gender, education and income are associated with the fish consumption frequency (Kaimakoudi et al., 2013). In line with the studies, this research study reports a significant correlation between age and purchase intention, between education and purchase intention, and between SK and OK. 


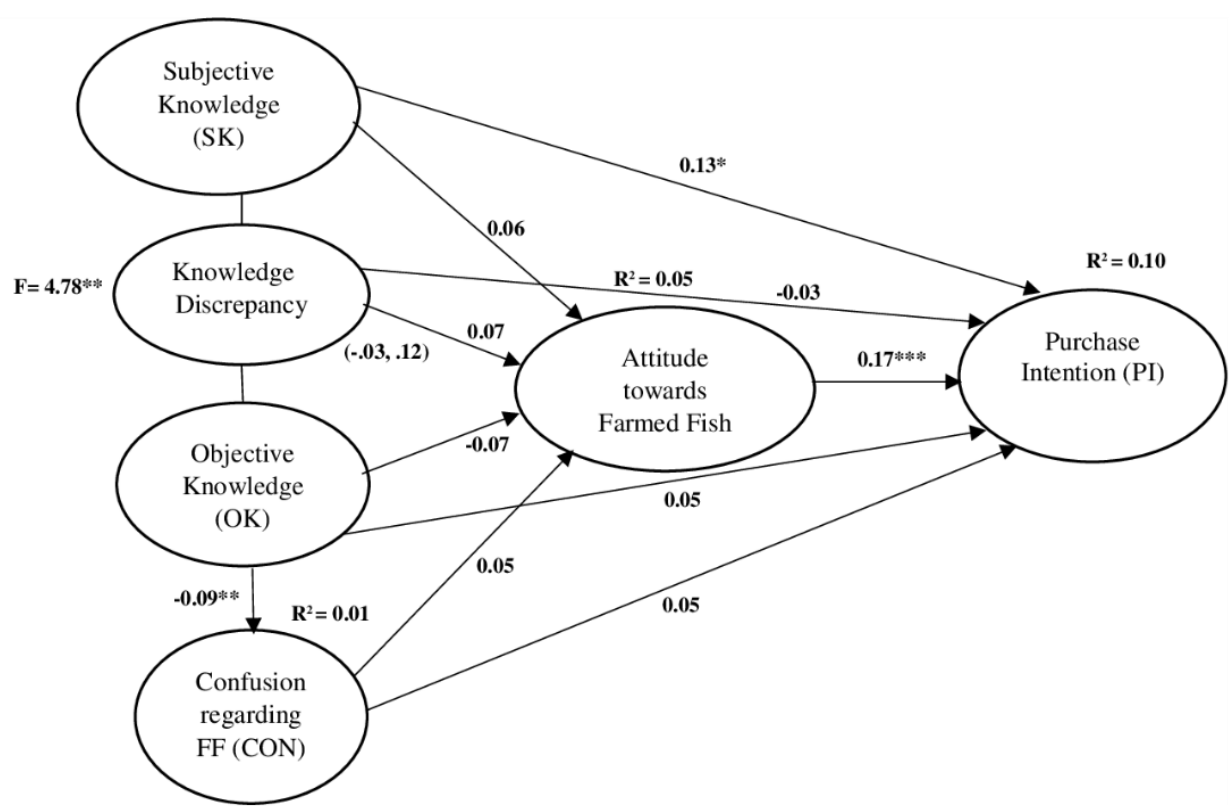

Figure 2: Results of hypotheses test.

\subsection{Conclusion and Implications}

This research has examined the influence of the knowledge, knowledge discrepancy, and confusion on consumer's attitude and purchase intention of farmed fish. To address this research question, a total of thirteen hypotheses were generated and tested. A survey with direct interview method was conducted to collect the relevant data. The knowledge and confusion scales were formed and then were regressed with SEM to observe whether the knowledge, knowledge discrepancy, and confusion have any effect on consumers' attitude and purchase intention of farmed fish. The results support that subjective knowledge positively influences the purchase intention of farmed fish. However, objective knowledge does not have any statistically significant effect on purchase intention of farmed fish. Furthermore, both objective and subjective knowledge cannot contribute significantly in forming the attitude towards farmed fish.

A crucial finding derived from this study is that subjective knowledge and objective knowledge are distinct constructs and each has a dissimilar effect on both attitude and purchase intention. This finding supports the prior research examining the effect of two components of knowledge types on consumers' food consumption behaviour in general, and fish consumption behaviour in particular. These findings are similar to those of Z Pieniak et al., (2010). In line with the previous studies (Carlson et al., 2009; Pieniak, Aertsens and Verbeke, 2010), this study reveals a statistically significant and positive association $(\mathrm{r}=0.35, \mathrm{P}<0.10)$ between subjective knowledge and Objective knowledge (Table 5). However, the comparatively an average, though statistically significant $(\mathrm{p}<.05)$, difference between subjective and objective knowledge $(\mathrm{F}=4.78, \mathrm{t}=-28.07, \mathrm{p}$ $=<0.05$ ) suggested a discrepancy among the knowledge level held by the consumer. This can be attributed to the argument that people may bear low knowledge than they perceive, or, they may underestimate their actual level of knowledge (Taylor and Brown, 1988).

The result revealed that consumers who overestimated their knowledge were found to bear a negative attitude toward farmed fish, while consumers who underestimated their actual (objective) knowledge had positive, although statistically not significant, attitude toward farmed fish. That 
means we can say, when they lack the actual knowledge they perceive farmed fish to be unfavorable, but when they have true knowledge they do not so. Thus, the information regarding aquaculture must not have been conveyed to them properly. However, the discrepancy do not bear any significant effect on the purchase intention.

Most participants (77\%) have a low or moderate level of objective knowledge pertaining to FF or aquaculture $(2.74 \pm 1.03)$. The study also found that more objective knowledge provides a lower confusion towards farmed fish, meaning that consumers with low level of objective (actual knowledge) knowledge are more confused than those with a high level of objective knowledge. This finding necessitates the so imminent importance of gathering knowledge as to provide support for the aquaculture to be flourished.

Surprisingly, the consumers with confusion do not differ in their attitude and purchase intention and the confusion have no bearing on attitude and purchase intention as well. Consequently, this result contradicts with the finding derived from green product purchase behavior that reveals that confusion regarding eco-levels inhibits the purchase likelihood of green products (Gracia and De Magistris, 2007). Since consumers' attitude and behaviour are culturally dependent concepts, it is normal to observe differences in the conceptualization of consumer confusion because of cultural differences (Ermeç Sertoğlu and Kavak, 2017). In addition, the actual level of confusion consumers do encounter in the time of purchasing FF may not be the same when they estimated during the time of response (Gunne and Matto, 2017). Finally, attitude towards FF has a positive significant effect on the purchase intention (Ajzen, 1991).

From the managerial perspective, the study substantiates with accentuating the fact that consumers of aquaculture have poor knowledge about aquaculture, suggesting that an effective strategy for public awareness should be framed through effective means of communication. Also the results reported by the study would have several implications. First, a more engaging consumer knowledge enhancement plan should be framed. Second, if the knowledge and information are provided from credible sources, the inherent perception could be shaped positively resulting in greater knowledge levels (Fortin and Renton, 2003). Marketers and other stakeholders can leverage this as an opportunity to build the way to provide the effective knowledge to benefit the users and to add value to the community. Previous literatures lack adequate support, till today, to address the relationship between objective knowledge and confusion, which, in turn, may impact the attitude and purchase intention of FF. To marketers, these findings may work as a word to gain the competitive advantage in commercializing the FF products. The distinct contribution of this study, which is yet to be recognized by the researcher, at least in the case of FF, is probably the measurement of a discrepancy of the knowledge held by the consumers. Additionally, the effect of overestimating the level of knowledge as well as underestimating the level of knowledge in explaining purchase intention of FF would be a supplementary addition in the field of research, aiding the stakeholders of the aquaculture to have a new dimension in recognizing the consumer behaviour from a different perspective.

However, authors think that future studies can take into account a greater dimension of knowledge. Future studies can also examine the effect of emotion, specific beliefs, perceived risks, trusts etc. as an explanatory variable in addition to outlined factors by the study along with a larger sample than the study uses. Finally, we took into account the effect of knowledge discrepancy on attitude and purchase intention, but the magnitude of this positive and negative discrepancy was not considered. Hence, the further examination can take this issue into account. 
Author Contributions: "Conceptualization, M.Z.H.; Methodology, M.Z.H.; Software, M.Z.H.; Validation, M.N.A; Formal Analysis, M.Z.H; Writing-Original Draft Preparation, M.N.A.; Writing-Review \& Editing, M.Z.H.; Visualization, M.N.A.; Supervision, M.N.A.; Project Administration, M.N.A; Funding Acquisition, M.Z.H.”.

Conflicts of Interest: The authors declare no conflict of interest.

\section{References}

Aertsens, J. et al. (2011) 'The influence of subjective and objective knowledge on attitude, motivations and consumption of organic food', British Food Journal, 113(11), pp. 1353-1378. doi: https://doi.org/10.1108/00070701111179988.

Ajzen, I. (1991) 'The Theory of Planned Behaviour. Organizational Behaviour and Human Decision Processes’, 50, pp. 179-211.

Awang, Z. (2012) 'Structural equation modeling using AMOS graphic', Penerbit Universiti Teknologi, MARA. ISBN 9789673634187.

Barber, N. et al. (2009) 'Environmental Knowledge and Attitudes : Influencing the Purchase Decisions of Wine Consumers'.

Brown, T. A. (2006) Confirmatory Factor Analysis for Applied Research, Methodology in the Social Sciences. doi: 10.1198/tas.2008.s98.

Brucks, M. (1985) 'The effects of product class knowledge on information search behavior”, Journal of Consumer Research', Journal of Consumer Research, 12, pp. 1-16.

Burns, R.P. and Burns, R. (2008). 'Business Research Methods and Statistics Using SPSS', SAGE Publications, ISBN=9781446204764.

Carlson, J. P. et al. (2009) 'Objective and Subjective Knowledge Relationships: A Quantitative Analysis of Consumer Research Findings', Journal of Consumer Research, 35(5), pp. 864-876. doi: $10.1086 / 593688$.

Claret, A. et al. (2014) 'Consumer beliefs regarding farmed versus wild fish is', Appetite. Elsevier Ltd, 79, pp. 25-31. doi: 10.1016/j.appet.2014.03.031.

DoF (2017) Yearbook of Fisheries Statistics of Bangladesh 2016-17. Dhaka, Bangladesh. Available at: https://goo.gl/9nFndS.

Ermeç Sertoğlu, A. and Kavak, B. (2017) 'A More Comprehensive View of Consumer Confusion: Scale Development', Journal of International Consumer Marketing, 29(4), pp. 265276. doi: 10.1080/08961530.2017.1295297.

Ertör, I. and Ortega-cerdà, M. (2015) 'Political lessons from early warnings : Marine fi n fi sh aquaculture con fl icts in Europe', 51, pp. 202-210.

Fernández-Polanco, J. and Luna, L. (2010) 'Analysis of perceptions of quality of wild and cultured seabream in Spain', Aquaculture Economics \& Management, 14(1), pp. 43-62.

Fernie, S. et al. (2003) 'Knowledge sharing: context, confusion and controversy.', International Journal of Project Management, 21(3), pp. 177-187. doi: https://doi.org/10.1016/S0263- 
7863(02)00092-3.

Field, A. P. (1999) 'Discovering statistics using SPSS for Windows', SAGE Publications Ltd, p. xii, $496 \mathrm{p}$.

Fortin, D. R. and Renton, M. (2003) 'Consumer acceptance of genetically modified foods in New Zealand', British Food Journal, 105, pp. 42-58.

Forza, C. and Filippini, R. (1998) 'TQM impact on quality conformance and customer satisfaction: a causal model', International journal of production economics, 55(1), pp. 1-20.

Froehlich, H. . et al. (2017) 'Public Perceptions of Aquaculture: Evaluating Spatiotemporal Patterns of Sentiment around the World', PLoS ONE, 12(1). doi: doi:10.1371/journal.pone.0169281.

Gracia, A. and De Magistris, T. (2007) 'Organic food product purchase behaviour: a pilot study for urban consumers in the south of Italy', Spanish Journal of Agricultural Research, 5, pp. 43951.

Greenspoon, P. J. and Saklofske, D. H. (1998) 'Confirmatory factor analysis of the multidimensional students' life satisfaction scale', Personality and Individual Differences, 25(5), pp. $965-971$.

Gunne, I. and Matto, J. (2017) 'The influence of subjective and objective knowledge of ecolabels on consumers ' green purchasing practices by', (May).

Hair, J. F. et al. (1998) 'Multivariate data analysis: with readings', (New Jersey: Prince Hall).

Hair, J. F. et al. (2006) 'Multivariate Data Analysis', 6(Pearson Prentice Hall, Upper Saddle River, NJ).

Hair, J. F., Black, WC, Babin, B. and Anderson, R. (2010) 'Multivariate data analysis', 7.

Haque, A. et al. (2015) 'Purchase Intention of Foreign Products : A Study on Bangladeshi Consumer Perspective', (10). doi: 10.1177/2158244015592680.

Hoque, M., Alam, M. and Nahid, K. (2018) 'Health Consciousness and Its Effect on Perceived Knowledge, and Belief in the Purchase Intent of Liquid Milk: Consumer Insights from an Emerging Market', Foods, 7(9), p. 150. doi: 10.3390/foods7090150.

House, L. et al. (2004) 'Objective and Subjective Knowledge : Impacts on Consumer Demand for Genetically Modified Foods in the United States and the European Union', 7(3), pp. 113123.

Huffman, Cynthia and Kahn, B. E. (1998) 'Variety for Sale: Mass Customization or Mass Confusion?', Journal of Retailing, 74(4), pp. 491-513.

J., M. et al. (2016) 'Consumer perceptions of farmed fish A cross-national segmentation in five European countries', British Food Journal, 118(10), pp. 2581 - 2597.

Kaimakoudi, E. et al. (2013) 'Consumers' attitudes towards fisheries products', Procedia Technology, 8, pp. 90-96.

Lessig, V. P. and Copley, T. P. (1974) 'Consumer beliefs, attitudes, and brand preferences', J. 
Acad. Mark. Sci., 2, pp. 357-366.

Liu, Y., Olaussen, J. and Skonhoft, A. (2011) 'Wild and farmed salmon in Norway: a review', Marine Policy, 35(3), p. 413. doi: http://dx.doi.org/10.1016/j.marpol.2010.11.007.

Lord, K. R. (1994) 'Motivating recycling behavior: A quasiexperimental investigation of message and source strategies', Psychology and Marketing, 11(4), pp. 341-358. doi: 10.1002/mar.4220110404.

Manach, C. et al. (2017) 'Addressing the inter-individual variation in response to consumption of plant food bioactives: Towards a better understanding of their role in healthy aging and cardiometabolic risk reduction', Molecular nutrition \& food research, 61(6).

Matzler, K., Stieger, D. and Füller, J. (2011) 'Consumer Confusion in Internet-Based Mass Customization: Testing a Network of Antecedents and Consequences', Journal of Consumer Policy, 34(2), pp. 231-247. doi: 10.1007/s10603-011-9157-6.

Park, C. W. et al. (1994) 'Consumer knowledge assessment', Journal of Consumer Research, 21(1), pp. 71-82.

Pieniak, Z., Aertsens, J. and Verbeke, W. (2010) 'Subjective and objective knowledge as determinants of organic vegetables consumption', Food Quality and Preference. Elsevier Ltd, 21(6), pp. 581-588. doi: 10.1016/j.foodqual.2010.03.004.

Pieniak, Z., Verbeke, W. and Scholderer, J. (2010) 'Health-related beliefs and consumer knowledge as determinants of fish consumption', pp. 480-488. doi: 10.1111/j.1365277X.2010.01045.X.

Prebensen, N. K. and Xie, J. (2017) 'Efficacy of co-creation and mastering on perceived value and satisfaction in tourists' consumption', Tourism Management, 60, pp. 166-176. doi: 10.1016/j.tourman.2016.12.001.

Rokeach Milton (1970) Beliefs Attitudes and Values., Jossey-Bass San Inc.: Francisco, CA, USA.

Schlag, A. K. and Ystgaard, K. (2013) 'Europeans and aquaculture: perceived differences between wild and farmed fish', British Food Journal, 115(2), pp. 209-222.

Selnes, F. and Gronhaug, K. (1986) 'Subjective and Objective Measures of Product Knowledge Contrasted', Advances in Consumer Research, 13, pp. 67-71.

Shamsuzzaman, M. M. et al. (2017) 'Fisheries resources of Bangladesh: Present status and future direction', Aquaculture and Fisheries, 2(4), pp. 145-156.

Takahashi, H. (1999) 'Clone technology and shipment of bovine embryo-cloned cattle', Chikusan no Jyouhou.

Taylor, S. E. and Brown, J. D. (1988) 'Illusion and well-being: a social psychological perspective on mental health', Psychological bulletin, 103(2), p. 193.

Verbeke, W. et al. (2007) 'Consumer perception versus scientific evidence of farmed and wild fish: Exploratory insights from Belgium', Aquaculture International, 15(2), pp. 121-136. doi: 10.1007/s10499-007-9072-7. 
Verbeke, W. (2008) 'Impact of communication on consumers' food choices.', The Proceedings of the Nutrition Society, 67(3), pp. 281-8. doi: 10.1017/S0029665108007179.

Verbeke, W. and Brunsø, K. (2005) 'Consumer awareness, perceptions and behaviour towards farmed versus wild fish', in The economics of aquaculture with respect to fisheries, 95th EAAE Seminar. Civitavecchia, Italy. The Hague, Netherlands: European Association of Agricultural Economists. 